\title{
Road Traffic Injury among Pedestrians in Dhaka City
}

\author{
Ahmad M', Rahman FN², Ali M³ Al-Azad MAS $^{4}$
}

\begin{abstract}
Introduction: Road traffic accident (RTA) is a growing public health problem worldwide. It is responsible for greatest number of injuries and fatalities by killing around 1.2 million people each year and injuring 50 million who occupy $30-70 \%$ of orthopedic beds in developing countries hospitals. Pedestrians are the most common victims of RTAs.
\end{abstract}

Objective: To find out the epidemiological factors and pattern of road traffic injury among pedestrians admitted at selected tertiary level referral hospitals in Dhaka City for getting necessary treatment.

Materials and Methods: This descriptive type of cross sectional study was done during December 2015 to June 2016 at four tertiary level referral hospitals in Dhaka. A total of 197 pedestrian patients were selected by purposive and convenient method of sampling. The primary data was collected from the patients after their discharge from hospital by face to face Exit interview using a pre tested semistructured questionnaire.

Results: Among 197 pedestrian victims interviewed; $129(65.48 \%)$ were male and $68(34.52 \%)$ female. Maximum accidents took place on city main roads 93(47.21\%), followed by internal roads $93(47.21 \%)$, maximum accidents occurred at day time $87(44.16 \%)$, followed by evening $49(24.87 \%)$. Regarding vehicles, highest number of accidents were caused by buses $63(31.97 \%)$, followed by mini bus $42(21.32 \%)$. Highest incidence of injuries was observed among the age group 21 to 30 yrs $81(41.12 \%), 168(85.27 \%)$ reported that they had been knocked down by the vehicles while crossing the roads (hit and run injury), 24(12.18\%) were injured by motor cycles moving at a speed illegally on the footpath, $56(28.42 \%)$ people fall on ground due to faulty roads and potholes, open manhole cover followed by vehicle's accident. Majority of victims $136(69.03 \%)$ were from earning group below 15,000 taka per month, most of the victims $155(78.68 \%)$ never used foot over bridge,168(85.27\%) person faced difficulty while walking through footpath due to piling of construction materials, selling items of neighboring shops etc, $127(64.47) \%$ were using mobile phone while crossing the road or walking through it. All the research samples had multiple abrasion and bruise all over the body, $164(83.25 \%)$ had lacerations in different body area, $85(43.14 \%) \%$ ) had fracture of upper limb bones, $69(35.03 \%)$ had fracture of lower limb bones .

Conclusion: The incidence and severity of injury of road accident can be prevented by motivation of public, strict application of traffic rules and proper training of drivers. More scientific research on road traffic injury are needed in future.

Key-words: Pedestrian Injury, Road Traffic Accident.

\section{Introduction}

Road traffic accidents (RTA) cause maximum number of injuries and fatalities worldwide. Around 1.2 million people are killed each year and 50 million injured by RTA who occupy $30-70 \%$ of orthopedic beds in hospitals ${ }^{1}$. With continuation of present trends by 2020 , road traffic injuries are predicted to be the third leading contributor to the global burden of disease ${ }^{2}$. In developing and poor countries $75 \%$ poor families who had a member affected by road traffic accident reported a decrease in their standard of living and $61 \%$ had to borrow money to

1. Lt Col Mushtaq Ahmad, MBBS, DFM, MCPS, FRSPH, Associate Professor and Head, Dept of Forensic Medicine, Armed Forces Medical College, Dhaka 2. Dr Farial Naima Rahman, MBBS, DMU, Lecturer, Dept of Forensic Medicine, Armed Forces Medical College, Dhaka 3. Brig General Mohammad Ali, MBBS, DPH, MPhil, Professor \& Head, Dept of Community Medicine, Armed Forces Medical College, Dhaka 4. Lt Col Md Abdus Samad Al-Azad, MBBS, DFM, MCPS, Assistant Professor, Dept of Forensic Medicine, Armed Forces Medical College, Dhaka. 
cover expenses following their loss. World bank estimates, road traffic injuries cost $1-2 \%$ of the gross national product (GNP) of developing countries ${ }^{3}$. In developing countries pedestrians, passengers and cyclists comprise $90 \%$ cases of Road traffic injuries ${ }^{4}$.

\section{Objectives}

This study was performed to find out the epidemiological factors and pattern of road traffic injury among pedestrians admitted at selected tertiary level referral hospitals in Dhaka City for getting necessary treatment.

\section{Materials and methods}

This is a descriptive type of cross sectional study done during December 2015 to June 2016 at four tertiary level referral hospitals namely Dhaka Medical college hospital, Sir Salimullah Medical College Hospital, Shaheed Suhrawardy Medical College Hospital and National Institute for Traumatology and Orthopaedic Rehabilitation (NITOR), Dhaka. A total of 197 pedestrians injured by RTA were selected by purposive and convenient method of sampling . The primary data was collected from the patients after their discharge from hospital by face to face Exit interview using a pre tested semi-structured questionnaire. A group of volunteer intern doctors, who were briefed earlier helped to identify the patients and collect the data. Inclusion criteria of research sample included pedestrian RTA victims aged 5 years to 65 years, who were physically and mentally sound to provide data for this research. For child victims, interview of parents was taken. Children below 5 years and elderly patients above 65 years were excluded. Ethical permission of authority concerned and verbal consent was obtained from every respondent pedestrians injured in RTA, who was informed that the researcher would maintain confidentially and anonymity of identity and the collected information would be used for research purpose only. They were also assured that no coercion or deception would be done to collect data and the data source would not be subjected to physical, chemical, biological or psychosocial intervention.

\section{Results}

Among 197 pedestrian victims interviewed; 129 $(65.48 \%)$ were male and 68(34.52\%) female. Maximum accidents took place on city main roads $93(47.21 \%)$, followed by internal roads $39(19.80 \%)$, cross junction $33(16.75 \%)$ and footpath $26(13.20 \%)$ (Table-I).
Table-I: Frequency distribution of places of occurrences $(n=197)$

\begin{tabular}{|l|c|}
\hline Places of occurrences & Number of victims f (\%) \\
\hline City main roads & $93(47.21 \%)$ \\
\hline Internal roads & $39(19.80 \%)$ \\
\hline Cross junction & $33(16.75 \%)$ \\
\hline Footpath & $26(13.20 \%)$ \\
\hline Railway crossings & $6(3.04 \%)$ \\
\hline Total & $\mathbf{1 9 7 ( 1 0 0 \% )}$ \\
\hline
\end{tabular}

Regarding time of accident, maximum occurred at day time $87(44.16 \%)$, followed by evening $49(24.87 \%)$ and morning 44(22.34\%) (Table-II).

Table-II: Frequency distribution of Time of RTAs $(n=197)$

\begin{tabular}{|l|c|}
\hline Time of accidents & Number of victims f(\%) \\
\hline Morning, 0501-0800 hrs & $44(22.34 \%)$ \\
\hline Day time, 0801- $1800 \mathrm{hrs}$ & $87(44.16 \%)$ \\
\hline Evening 1801-1930 hrs & $49(24.87 \%)$ \\
\hline Night 1931- $0500 \mathrm{hrs}$ & $17(8.63 \%)$ \\
\hline Total & $\mathbf{1 9 7 ( 1 0 0 \% )}$ \\
\hline
\end{tabular}

Regarding vehicles, highest number of accidents were caused by buses $63(31.97 \%)$, followed by mini bus $42(21.32 \%)$, truck $33(16.76 \%)$, motor cycle $24(12.18 \%)$ and pick up $15(7.61 \%)$ (Table-III).

Table-III: Frequency distribution of types of vehicles involved in accidents $(n=197)$

\begin{tabular}{|l|c|}
\hline Name of vehicles & Number of victims f(\%) \\
\hline Bus & $63(31.97 \%)$ \\
\hline Mini bus & $42(21.32 \%)$ \\
\hline Truck & $33(16.76 \%)$ \\
\hline Motor cycle & $24(12.18 \%)$ \\
\hline Pick up & $15(7.61 \%)$ \\
\hline Micro bus & $9(4.57 \%)$ \\
\hline Private cars & $7(3.56 \%)$ \\
\hline CNG & $4(2.03 \%)$ \\
\hline Total & $\mathbf{1 9 7 ( 1 0 0 \% )}$ \\
\hline
\end{tabular}

Highest incidence of injuries was observed among the age group 21 to 30 yrs $81(41.12 \%)$, followed by $63(31.98 \%)$ among age group 31 to 40 years and $41-50$ years $21(10.66 \%$ ) (Table-IV).

Table-IV: Frequency distribution of Age of RTA victims ( $n=197$ )

\begin{tabular}{|l|c|}
\hline Age in years & Number of victims f(\%) \\
\hline $5-10$ & $8(4.06 \%)$ \\
\hline $11-20$ & $12(6.09 \%)$ \\
\hline $21-30$ & $81(41.12 \%)$ \\
\hline $31-40$ & $63(31.98 \%)$ \\
\hline $41-50$ & $21(10.66 \%)$ \\
\hline $51-60$ & $7(3.55 \%)$ \\
\hline $60-65$ & $5(2.54 \%)$ \\
\hline Total & $\mathbf{1 9 7 ( 1 0 0 \% )}$ \\
\hline
\end{tabular}


Fifty six $(28.42 \%)$ people fall on ground due to faulty roads and potholes, open manhole cover, followed by hit by vehicles. Among the research samples, 168 ( $85.27 \%$ ) reported that they have been knocked down by the vehicles while crossing the roads (hit and run injury), $24(12.18 \%)$ were injured by motor cycles moving at a speed illegally on the footpath. One hundred sixty eight $(85.27 \%)$ person said they faced difficulty while walking through footpath due to piling of construction materials, selling items of neighboring shops, cluster of hawkers and parking of vehicles on footpath.

One hundred and twenty seven (64.47)\% said they were using mobile phone while crossing the road or walking through it. Most of the victims $155(78.68 \%)$ never used foot over bridge, while $42(21.32 \%)$ occasionally used foot over bridge. Majority of victims 136(69.03\%) were from earning group below 15,000 taka per month, $38(19.29 \%)$ had monthly earning between 15,001-20,000 taka and $23(11.68 \%)$ earned more than 20,000 taka per month.

All the research samples had multiple abrasions and bruises all over the body, 164(83.25\%) had lacerations in different body area, $85(43.14 \%) \%$ ) had fracture of upper limb bones, 69(35.03\%) had fracture of lower limb bones and $63(31.98 \%)$ had haematoma in the soft tissue over skull (Table-V).

Table-V: Frequency distribution of Pattern of injury in victims $(n=197)$

\begin{tabular}{|l|c|}
\hline Pattern of injury in pedestrians & Number of victims f(\%) \\
\hline Multiple abrasions & $197(100 \%)$ \\
\hline Multiple bruise & $197(100 \%)$ \\
\hline Laceration & $164(83.25 \%)$ \\
\hline Fracture of upper limbs bones & $85(43.14 \%)$ \\
\hline Fracture of lower limbs bones & $69(35.03 \%)$ \\
\hline Haematoma over soft tissue skull & $63(31.98 \%)$ \\
\hline Intracranial injury & $55(27.92 \%)$ \\
\hline Fracture of ribs & $38(19.29 \%)$ \\
\hline Injury to Abdominal viscera & $3417.26 \%)$ \\
\hline Fracture of pelvis & $16(8.12 \%)$ \\
\hline Fracture of skull & $6(3.05 \%)$ \\
\hline
\end{tabular}

N.B: same victim had multiple types of injury.

\section{Discussion}

Bangladesh is densely populated country where due to poverty and unemployment people from rural areas rush towards city. Pedestrians are the most vulnerable road users in Bangladesh. The choice of mode of transport in developing countries is often influenced by socioeconomic factors, especially income ${ }^{5}$. In Dhaka Metropolitan City people use rickshaws, CNG and other types of slow moving vehicles along with fast moving motor vehicles which make the traffic worse and the city roads become hostile to pedestrians ${ }^{6-9}$.

In urban areas of Bangladesh only pedestrians represents often up to 70 percent of road accident fatalities. Current statistics revealed a deteriorating situation in metropolitan Dhaka. For example, in 1996-98 the number of pedestrian casualties (fatalities and injuries) has increased markedly from 443 in 1996 to 588 in 1998, an increase of about 29 percent. Pedestrians are now making up approximately 73 percent of road accident fatalities, 26 percent of injuries and are involved in about 43 percent of all reported accidents ${ }^{10}$.

Approximately $33 \%$ of the beds in primary and secondary level hospitals in Bangladesh were occupied by injuryrelated patients and more than $19 \%$ had been injured in a road traffic accident. People aged $18-45$ years were the major victims of RTA and constituted $70 \%$ of the total RTA-related admissions in primary and secondary level hospitals ${ }^{10}$. The estimated national cost of road accident is Tk. 38 billion or US\$ 644 million. This is said to be 1.5 percent of Gross Domestic Product (GDP) and three times annual expenditure of the Road and Highways Department $(\mathrm{RHD})^{11}$. Globally, in $1998,51 \%$ of fatalities and $59 \%$ of disability adjusted life years lost due to road traffic injuries occurred in the productive age group ${ }^{12}$. The trend of increasing numbers of injuries is likely to continue as the number of motor vehicles rises.

In this study male pedestrians were more than females. Men are at higher risk of injuries than women because in our country they are predominantly the earning member of the family and have greater exposure to traffic. In Dhaka city a large number of pedestrian are garment employees, day labourers, construction workers, house maids, street hawkers etc who lack basic knowledge regarding traffic rules and there is also scarcity of footpath along road sides making them vulnerable to accidents.

Maximum accidents occurred at daytime followed by evening. There is increase traffic load on road at daytime due to rush of passengers towards offices, educational institutes and work places. Sleeping tendency among drivers at night, poor visuality, lack of luminescence marking on road, potholes, open manholes in roads, 
overtaking, increase number of cargo vehicles on road are also responsible for accidents at night. Maximum accidents took place on main roads, internal roads and cross junction respectively which are places in city areas where heavy vehicles run throughout the day and night.

Considering vehicles; highest number of accidents were caused by buses, followed by mini bus, truck and motor cycle which are common vehicles in city. These vehicles lack relevant safety standards. Road transport plays an important role in Bangladesh. Earlier studies by Hoque on road accidents in Dhaka also revealed that heavy vehicles such as buses, trucks and minibuses are major contributors to road accidents $^{13,14}$. In this study, Highest incidence of RTA was observed among the age group 21 to $30 \mathrm{yrs}$, followed by among age group 31 to 40 years. Majority of the victim belong to their most productive earning years. proportion in extreme age group (below 10 years and above 60 years) could be due to the fact that children are usually taken care of by elders during travel and geriatric people has lesser mobility. The findings coincides with earlier studies which showed road traffic injuries in developing countries affect the productive (working) age group (15-44 years) and children ${ }^{15-20}$.

Hit and run indicates the drivers don't care about traffic rules or punishments and they drive vehicles at over speed than permissible limit. The law enforcing agencies are also somehow reluctant to take the culprits into books. Maximum people fall on ground due to faulty roads and potholes, open manhole cover, which shows lack of maintenance of footpaths. In absence of walkway people come on main roads and fell victim of RTAs. Absence of foot over bridge at required places, use of mobile phone and remaining inattentive while walking through roads, face to face collision with motor bikes on footpath are also very common cause of RTAs now a days in Dhaka city. Bikers use footpath to short cut their way, during heavy traffic jam, which is a new finding in this research and an emerging problem in Dhaka city now a days.

Regarding injury to different body parts, all the victims received multiple abrasions and bruise in all over the body, lacerations and Internal injury to abdominal organs occurred due to fall on ground and sudden impact by vehicles. Fracture of upper limbs bones and lower limbs bones occur mostly by crush injury caused by vehicles wheels. Fracture and haematoma over skull occurs due to fall on ground and sudden impact on head which strikes by forcible contact with broad resisting surface like the roads. The thinnest area in our skull is the temporal bone $(4 \mathrm{~mm})$ followed by frontal bone $(6 \mathrm{~mm})$, parietal bone $(10 \mathrm{~mm})$ and occipital bone $(15 \mathrm{~mm})$. Fracture depends on the position of head fallen on ground and received impact injury ${ }^{21}$. Result and findings of this research coincides with previous researches done on this subject both home and abroad $^{22-26}$.

\section{Conclusion}

The incidence and severity of injury of road accident can be prevented by raising awareness of public, strict application of traffic rules and proper training of drivers, removal of unfit vehicles, repair of roads etc. Community clinic can be installed beside road to reduce the causality of victims. More scientific research on road traffic injury are needed in future.

\section{References}

1. Mohan D. Road safety in less motorized environments. Future Concerns, " Int J Epidem 2002; 31(3):527-32.

2. Murray CJL, Lopez AD. The Global Burden of Disease. A Comprehensive Assessment of Mortality and Disability from Diseases, Injuries and Risk factors in 1990 and projected in 2020. Harvard School Public Health 1996; 1:1-25.

3. Peden $M$ and Hyder AA. " Road traffic Injuries are a Global Public Health Problem. BMJ 2002; 324:1153-54.

4. Hijaar MC. Traffic injuries in Latin American and the Caribbean countries, 1999. www.globalforumhealth.org/ Non compliant_pages/ forum3/ Forum3doc962.htm (accessed 11 May 2014).

5. Kapila S, Manundu M, Lamba D. The "matatu" mode of public transport in metropolitan Nairobi. Nairobi: Mazingira Institute Report, 1982.

6. Hoque, MM. "Pedestrian Safety in Dhaka", proceedings of the 7th Road Engg. Association of Asia and Australasia Conference, Singapore, June 1992.

7. Hoque MM. The road accident situation in Bangladesh. Technical paper, Conference of Asian Road Safety (CARS), Kuala Lumpur, October 1993.

8. Hoque MM. "Strategies for road safety: the Bangladesh situation", Proc. The Third International Conference on Safe Communities, Harstad, Norway, 6-8 June 1994.

9. Hoque MM. "Towards improving road safety in Bangladesh", XXth PIARC World Road Congress, 3-9 September 1995, Montreal, Canada.

10. Hoque MM. The road to road Safety: Issues and Initiatives in Bangladesh Proceedings of the 2nd Asian Regional Conference on Safe Community and 1st Bangladesh Conference on Injury Prevention, 15-17 February, 2004, Dhaka. 
11. Ali AMMS. The Economic Cost of Road Accidents in Bangladesh, The Daily Star 2004, April 18,1:1-16.

12. Krug E. ed. Injury: a leading cause of the global burden of disease. Geneva: WHO, 1999. www.who.int/ violence_injury_ prevention/index.html (accessed 11 May 2014).

13. Hoque MM. Road safety audit in developing countries. Transportation Research Group, Dept of Civil \& Environmental Engg, University of Southampton Journal of Engineering Science and Technology 2011; 6(4):493-505.

14. Hoque MM. Road planning and engineering for promoting pedestrian safety in Bangladesh. Proceedings of 10th Road Engineering Association of Asia and Australia (REAAA) Conference, Tokyo 2000.

15. Ansari S, Akhdar F, Mandoorah $\mathrm{M}$ et al. Causes and effects of road traffic accidents in Saudi Arabia. Public Health 2000; 114(1):37-9

16. Banerjee KK, Agarwal BB, Kohli A et al. Study of head injury victims in fatal road traffic accidents in Delhi. Indian J Med Sci 1998; 52(9):395-8.

17. Jha N, Srinivasa DK, Roy G et al. Injury pattern among road traffic accident cases: A study from South India. Indian Journal of Community Medicine 2003; 28(2):85-90.

18. Majumdar B, Karmakar R, Bose $\mathrm{T}$ et al. Some host factors and seasonal variations in the fatal road traffic accidents occurring in eastern suburban Calcutta. Indian $J$ Public Health 1996; 40(2):46-9.
19. Maheshwari J, Mohan D. Road traffic injuries in Delhi: A hospital based study. J Traffic Medicine 1989; 17(3-4):23-7.

20. Romo F, Nizamo H, Mapasse $D$ et al. Road traffic injuries in Mozambique. Inj Control Saf Promot 2003; 10(1-2):63-7.

21. Reddy KSN. The Essentials of Forensic Medicine \& Toxicology. 33rd ed. Health Sci Publisers, New Delhi India $2014 ; 257-63$

22. Ahmad M, Rahman FN, Sarker MMI et al. Pattern of Injury in Fatal Road Traffic Accidents: A Study of 100 Postmortem Cases. JMCWH 2007; 5(2):78-84.

23. Krug E, ed. Injury: A leading cause of the global burden of disease. Geneva: WHO, 1999. www.who.int/ violence_injury_prevention/index.html (accessed 11 May 2014).

24. Mashreky SR, Rahman A, Khan TF et al. Hospital burden of road traffic injury: major concern in primary and secondary level hospitals in Bangladesh. Public Health 2010 April; 124(4):185-9.

25. Jaishwal K, Kumer S, Sant SK et al. Injury patter on road traffic accident cases in a rural hospital of Central Uttar Pradesh. Int J med Sci and Pub Health 2016; 10(4):1347-50.

26. Gunveer GV, Tiwari RR. Injury pattern among non fatal road traffic accident cases: A cross sectional study in Central India. Indian J Med Sci 2005; 59(1):9-12. 